\title{
Boundaries and boundary objects: an evaluation framework for mixed methods research
}

\author{
Beverly Wenger-Trayner, Etienne Wenger-Trayner, Josh Cameron, Suna Eryigit-Madzwamuse, \\ and Angie Hart \\ University of Brighton, UK
}

\begin{abstract}
Author note
Beverly Wenger-Trayner, Grass Valley, California; Etienne Wenger-Trayner, School of Social Sciences, University of Brighton; Josh Cameron, School of Health Sciences, University of Brighton; Suna Eryigit-Madzwamuse, Centre for Health Research, University of Brighton; Angie Hart, School of Health Sciences, University of Brighton

We would like to thank all current and former Imagine Program - Social Context group members including academics, community partners, practitioners, young people and policymakers. This study was funded in part by grant ES/K002686/2 from the Economic and Social Research Council (ESRC). The contents are solely the responsibility of the authors and do not necessarily represent the official view of the ESRC. Information on ESRC is available on http://www.esrc.ac.uk/
\end{abstract}

Correspondence concerning this article should be addressed to Beverly Wenger-Trayner. Email: bev@wenger-trayner.com 


\begin{abstract}
While mixed methods research is increasingly established as a methodological approach, researchers still struggle with boundaries arising from commitments to different methods and paradigms, and from attention to social justice. Combining two lines of work-social learning theory and the Imagine Program at the University of Brighton-we present an evaluation framework that was used to integrate the perspectives of multiple stakeholders in the program's social interventions. We explore how this “value-creation framework” acts as a boundary object across “boundaries of practice”, specifically across quantitative and qualitative methods, philosophical paradigms, and participant perspectives. We argue that the framework's focus on cycles of value creation provided the Imagine Program with a shared language for negotiating interpretation and action across those boundaries.
\end{abstract}

Key words: boundaries, boundary object, value-creation framework, evaluation, social learning 
Mixed methods research is establishing itself as a distinct methodological approach, with a plethora of publications, a journal, and an association. At the same time, as an emerging field, it struggles with theoretical and implementation challenges beyond simply including quantitative and qualitative methods in a study, as outlined in a recent Task Force report (MMIRA, 2016). In her introduction to the Oxford Handbook of Multimethod and Mixed Methods Research Inquiry, Hesse-Biber (2015) describes these challenges as border challenges across chasms: "How can a qualitative researcher, for example, assess the importance and meaning of the quantitative data collected?” (xi) She refers to epistemic tensions at the border between different paradigms and communication chasms across disciplinary boundaries: the challenge of negotiating data collection, analysis, and interpretive frames. She regrets that "in effect we are still witnessing the publication of parallel quantitative and qualitative components” (xii). She also describes tensions related to axiological differences in commitments to include diverse voices and foster social justice.

It is regarding these boundaries that we believe we have something to offer. Our contribution to these debates was born out of the convergence of two lines of inquiry: work from social learning theory by the first two authors was adopted for the mixed methods evaluation of a social intervention involving the last three authors. The Imagine Program at the University of Brighton is a large-scale series of social interventions to increase the resilience of young people and adults who face difficult life situations. To develop these interventions the Imagine Program mobilized and combined diverse sources of expertise from a range of academic disciplines; health, education and community practitioners; and from the lived-experience of people facing a spectrum of health and social adversities. It involves fifteen local participatory projects across seven countries in contexts such as schools, families, and social services 
(http://www.imaginecommunity.org.uk/projects/the-social-context/). The evaluation team has adopted a mixed-method approach that integrates quantitative and qualitative data streams. The researchers come from different backgrounds and paradigms. And the participatory approach to co-production of research involves a variety of constituents. The Imagine Program draws heavily on social learning theory, hence a model derived from social learning theory provides a useful framework to structure an evaluation process that integrates the methods and perspectives of multiple stakeholder groups. For simplification, the paper is written in the voice of the first two authors, but it is the fruit of our collaboration.

\section{Social Learning Theory}

We are social learning theorists who use our consultancy work to refine and develop our theories and models. The practical consequence of a learning theory is to shape how we understand and support learning. In a world with increasingly complex learning challenges, the tools of social learning theory have the potential to speed up the human capability to respond.

Unlike individual perspectives that focus on the acquisition of information and skills, social learning theory focuses on participation in social practices. It is as social beings that we humans give meaning to our experience of the world, account for the actions we take, and develop a sense of who we are. Learning transforms our human ability to make meaning and participate in the world. It shapes our identity.

A central concept in our social learning theory is that of a community of practice (Wenger, 1998). Our work with this concept is relevant to this paper in two ways. First, the challenge of evaluating communities of practice has pushed us to develop an evaluation framework for social learning that integrates various data streams and makes sense to participants, evaluators, and stakeholders. It is this framework that we introduce in this paper. ${ }^{1}$ 
Second, boundaries are salient features in our theory of learning. Communities of practice are formed through shared histories of learning. Over time these histories inevitably create boundaries between those who have been participating and others (Wenger, 1998). In our more recent work on learning in landscapes of practice, where learning capability involves multiple communities of practice, boundaries have become even more salient. While “boundaries are places of potential misunderstanding and confusion arising from different regimes of competence, commitments, values, repertoires, and perspectives," they also "hold potential for unexpected learning.” (Wenger-Trayner and Wenger-Trayner, 2014) Rather than trying to eliminate boundaries we propose treating boundary encounters as potential learning opportunities. Trying to foster learning beyond single practices has led us to engage with serious boundaries among communities whose members experience the world very differently—the chasms that Hesse-Bieber refers to. As such, our consultancy work dovetails with a view of mixed methods inquiry as a cross-boundary endeavor inviting "respectful conversation, dialogue, and learning one from the other, toward a collective generation of better understanding...” (Greene, 2007:xii).

\section{Boundary Objects}

Our work on boundaries has highlighted the role of boundary objects. The term boundary object was coined by Leigh Star to describe how zoological specimens serve as common reference points in coordinating the perspectives of the distinct social worlds of scientists who analyze them and amateurs who collect them in the wild (Star and Griesemer, 1989). Boundary objects must be simultaneously concrete and abstract, simultaneously fluid and well-defined. (ibid: 409) to enable different groups to coordinate their actions without a consensus about their aims and interests. Eser (2002) argues that boundary objects often have 
enough malleability to be politically successful. She gives the example of the concept of sustainability, which has become a boundary object providing common ground for ecologists and economists in spite of their different perspectives.

In social learning theory, the concept of boundary object was adopted to refer to artifacts that function at the boundaries between communities of practice (Wenger, 1998). These boundary objects allow members of different communities to interact productively, from merely enabling coordination (e.g., a set of instructions) to providing windows into another practice (e.g., a documentary). In our practical work, we have seen the importance of having wellstructured boundary objects to mediate the negotiation of meaning and approaches across "boundaries of practice." We believe that our evaluation framework is relevant to the mixed methods community precisely because it can act as such a boundary object.

In this paper, we first provide a brief overview of our "value-creation framework" as an evaluation template for integrating multiple data streams. Then we explore how it can act as a boundary object across three types of boundaries significant to the mixed-method community boundaries across methods, across paradigms, and across participant perspectives. We use the experience of the Imagine Program to ground our argument in practice. In conclusion, we suggest avenues for further exploration.

\section{A “Value-Creation” Perspective on Social Learning}

The simple version of social learning is straightforward. What people do in their practices, what they try and whether it works or not, all contains information that is a potential resource for someone else. Through participation in learning interactions they gain new insights and resources that lead them to change their practice, with, one hopes, improved results. This may even transform them or their environment. Learning comes full circle when they feed back 
these effects into their communities. It is these loops between learning interactions, insights, practice, results, and back that we call social learning.

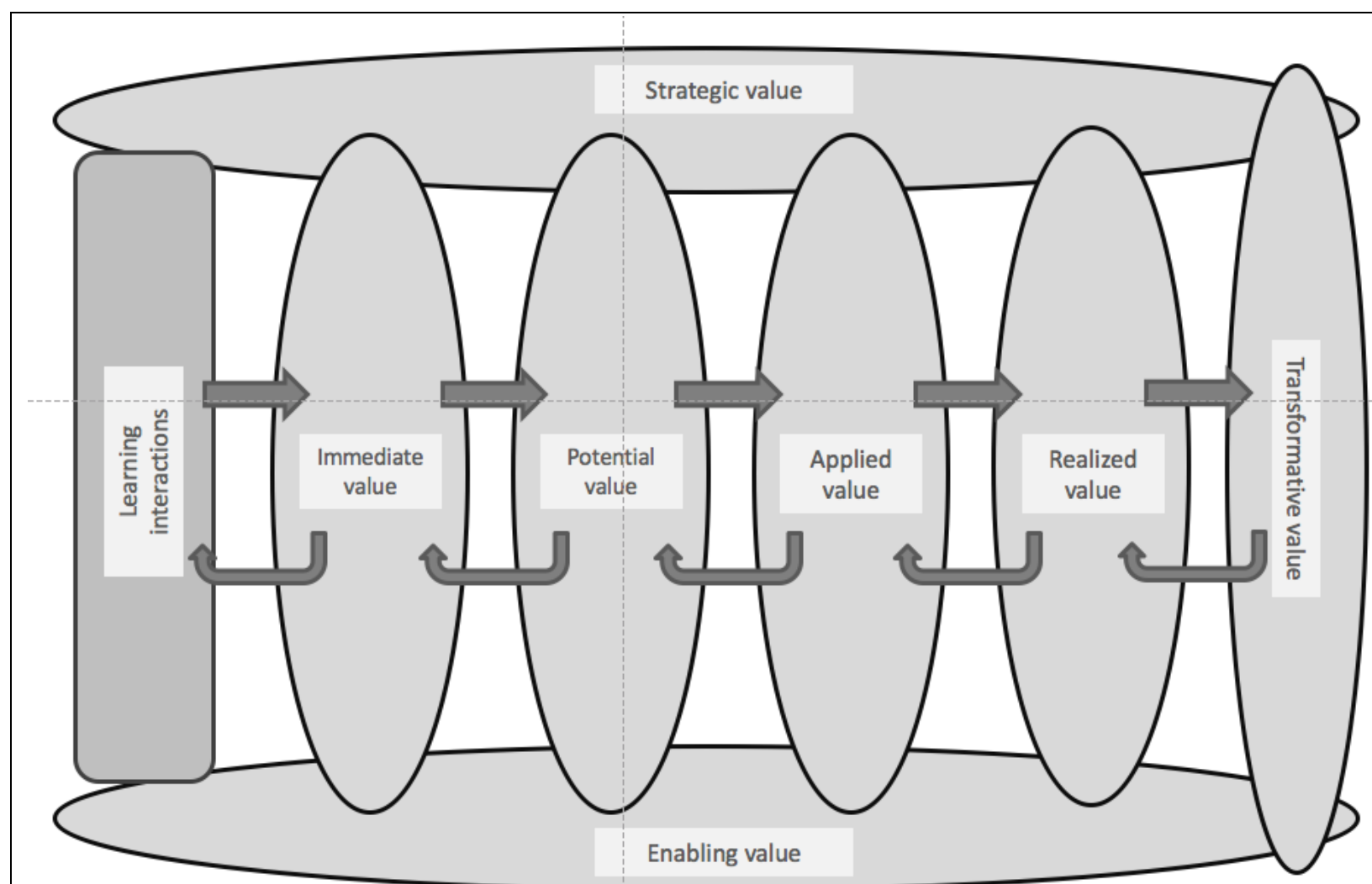

Figure 1. Value-creation framework

Our evaluation framework, illustrated graphically in Figure 1, builds on this

straightforward model. We see each step of the learning process as creating value-or not.

Value here refers to importance, worth, or usefulness rather than moral standards, even if the two are related. Our framework includes seven value-creation cycles: (i) engaging in a social learning interaction can produce immediate value, such as enjoying the company of like-minded people or doing something exciting; (ii) this engagement can generate potential value such as 
insights, connections, or resources; (iii) drawing on these insights, connections, or resources to change one's practice requires much creativity and learning, and thus is viewed as generating applied value; (iv) to the extent that changes in practice make a difference to what matters, social learning produces realized value; (v) if it transforms people’s identities or the broader environment, we say that it has produced transformative value; (vi) successful communities engage with relevant stakeholders to ensure that their learning makes a difference: the quality of these conversations and relationships produces strategic value; (vii) and getting better at supporting or enabling social learning produces enabling value. In this framework social learning is theorized as loops that carry value creation across cycles and back.

\section{Evaluating Social Interventions: Effects and Contribution}

This framework provides an evaluation template for social interventions-interventions in a social context where impact depends on the value that relevant actors find in the intervention. The evaluation of social interventions is challenging because effects are indirect and often attributable to multiple factors. As a result, the evaluation needs to make two related but distinct claims. The first claim is that there is some effect on things that matter to stakeholders; the second is that at least some of this effect can be plausibly attributed to the intervention. This requires two types of data: (i) effect data about changes that matter; and (ii) contribution data about the plausible role of the intervention. We will talk about contribution rather than attribution to acknowledge the complex nexus of causal factors typical of social contexts (Mayne, 2012; Leeuw, 2016). By tracing value-creation from intervention to outcomes, the framework defines the form that these two types of data should take to strengthen the overall evaluation. 


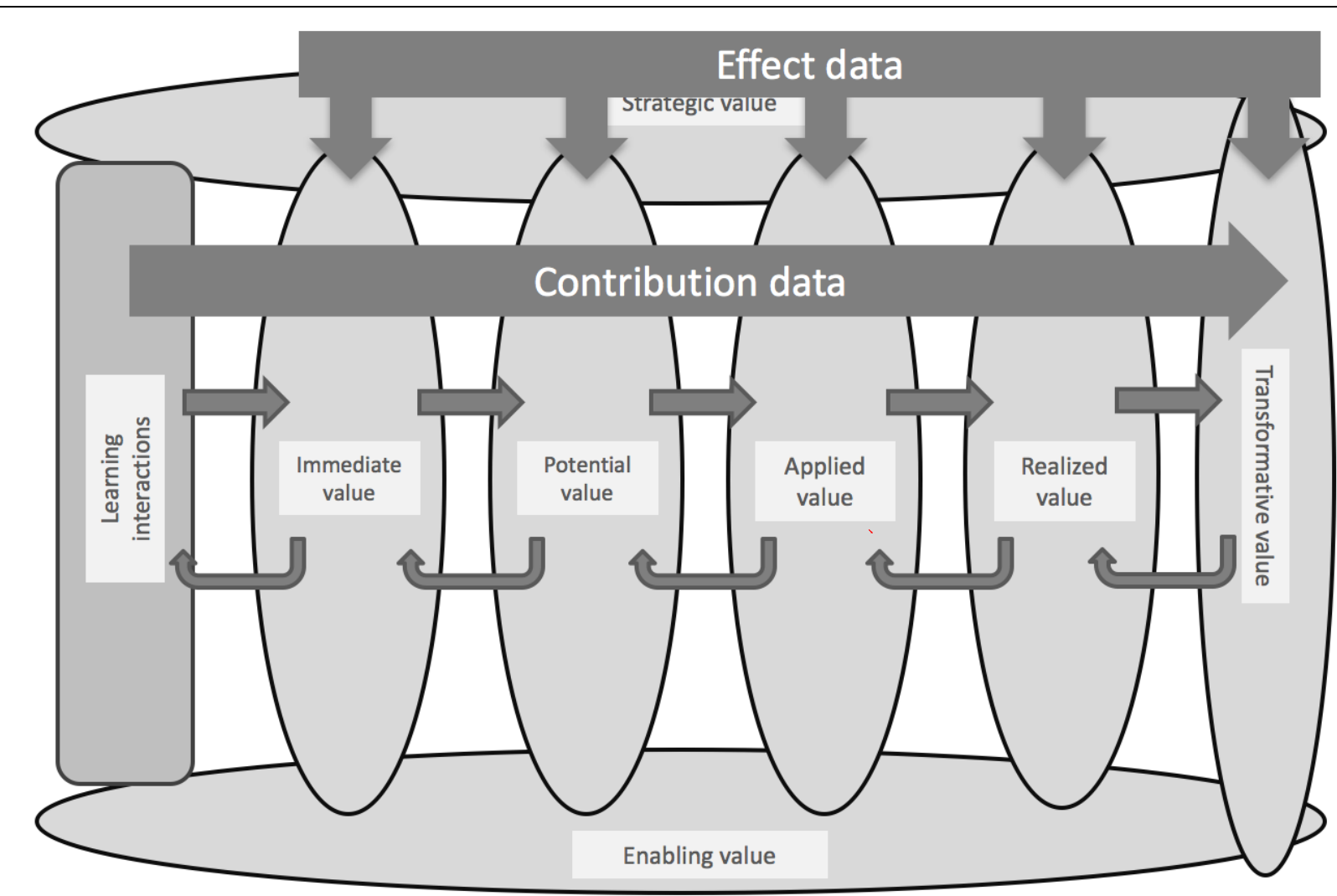

Figure 2. Effect and contribution data

Effect data. The framework’s value-creation cycles provide categories for effect data. We use the term effect data, rather than outcome or impact data, because the evaluation process needs to collect data about effects at each cycle, not only for realized or transformative value, which for most people would be outcome or impact. Collecting data for each value cycle accounts for the complex ways in which an intervention creates value. Effect data can be quantitative or qualitative. The advantage of including quantitative effect data is to assess effects at scale, in the aggregate, beyond individual claims or experience. Figure 3 shows examples of ways the Imagine Program assesses effect-data at each cycle. 


\section{Strategic}

Reactions by policy-makers and lobbyists to the use of a collaborative approach to build resilience for adults with mental health problems and young people - measured by attendance levels at policy oriented meetings and frequency of follow-up requests

Quality of collaboration among academic and nonacademic partners - assessed through rating scales and semi-structured and focus group interviews with different partners

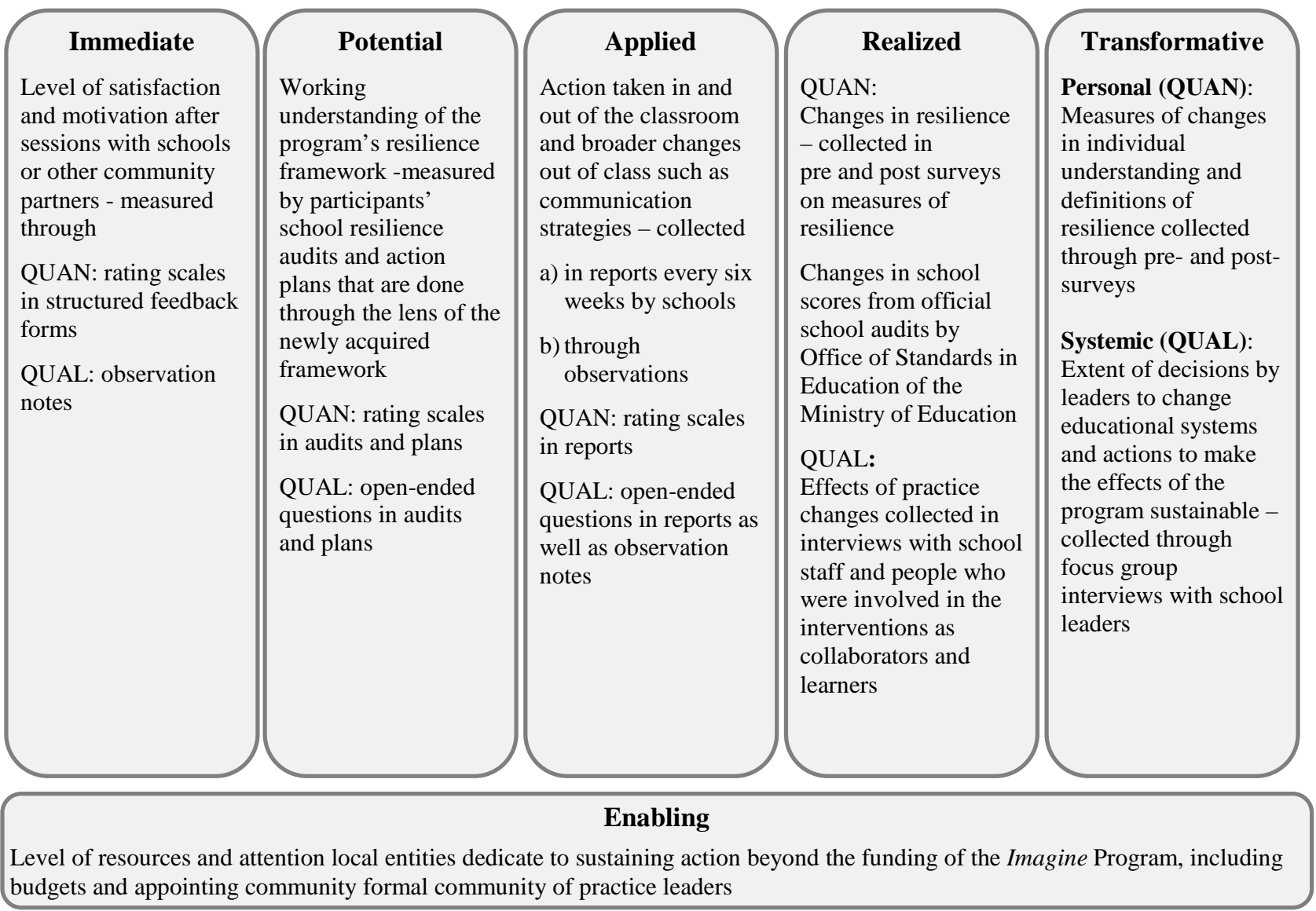

Figure 3. Examples of effect data from the Imagine Program.

Contribution data. Contribution presents a different challenge. To attribute an effect to an intervention, traditional quantitative methods rely on control of variables or elimination of rival hypotheses so that there is only one possible causal factor. In social interventions, this type of tight control is not possible. Our framework suggests another avenue. In addition to effect data for each cycle, researchers collect cross-cycle data in the form of "value-creation stories". The framework defines a specific genre for these stories: they connect specific activities to 
outcomes by going through each intervening value cycle, with each cycle marking a rhetorical move in the story. Figure 4 provides an example of such a story told by a participant in the Imagine Program. To the extent that value-creation stories follow the genre and are told by participants who personally acted as carriers of value-creation across the framework, they help build a plausible case that the intervention contributed to changes in practice that made a difference.

Cross-reference. This ability to act as contribution data is amplified if the stories crossreference effect data collected in the value cycles. For instance, the story in Figure 4 shows how the intervention contributes to transformative effects measured in Figure 3. Effect data alone risk confounding other contributing factors; contribution data alone risk missing the overall picture of the impact. The robustness of an evaluation depends on the integration of effect and contribution data. 


\section{Strategic}

A mental health Recovery College agreed to explore new service-delivery models by hosting an Imagine project in which people with a history of mental health problems pair up with professionals to provide peer training on resilience using the Imagine "Resilience Framework."

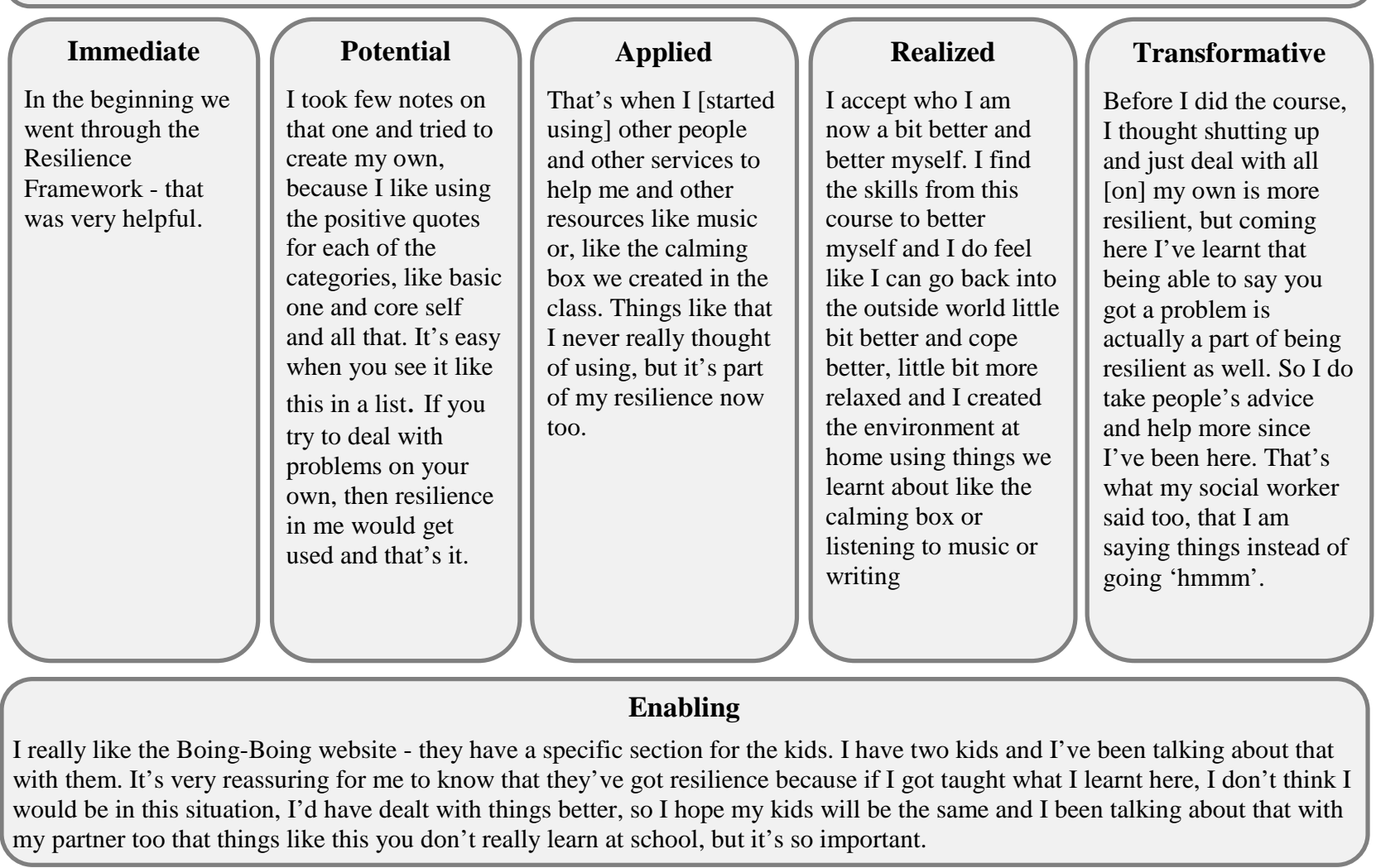

Figure 4. A value-creation story

\section{Acting as a Boundary Object}

Using our collaboration with the Imagine Program as an example, we now discuss how the framework acts as a boundary object for three types of boundaries familiar to the mixed methods community:

- Methods: bridging quantitative and qualitative methods, i.e., what data to collect and how to integrate data streams

- Paradigms: bridging the perspectives of various paradigms, i.e., what counts as fact and what counts as knowledge 
- Ethical stances: bridging between researchers and participants, i.e., how to include the voice of lived experience and issues of social justice ${ }^{2}$

Note that the goal of using a boundary object is not to reconcile differences across boundaries, but to allow participants to proceed together despite, or even while leveraging, differences.

\section{Bridging Methods}

“Around what does the mixing happen?” (Jennifer Greene, 2008:17)

The most obvious area in which the mixed methods community struggles with a boundary is between qualitative and quantitative methods. In the first issue of the Journal of Mixed Methods Research, Bryman states that "a significant difficulty is that of merging analyses of quantitative and qualitative data to provide an integrated analysis.” (2007: 20) And recently, Hesse-Bieber still sees the "thorny issues of what to do with data gathered across quantitative and qualitative divides” as “a challenge that continues to plague the field of MMR” (2015: xi).

In the Imagine Program, a large part of effect data is quantitative and contribution data qualitative. Integrating the two is a mixed-method challenge and brings out methodological issues familiar to mixed-method researchers. What form should quantitative and qualitative data take to serve each other? And how does one integrate them systematically throughout the research process? Researchers have found that the value-creation framework provides a structured way to address these issues.

\section{A Grammar for Integration}

The value of a boundary object lies in acting as a pivot between perspectives across a boundary. A formal, well-structured boundary object goes further: it provides a kind of integrative grammar for defining well-formed contributions that will be useful to the other side. 
In our case, the framework defines well-formed statements for effect and contribution that are likely to enable integration.

Well-formed effect data. Good effect data provide robust information with the following characteristics:

- They cover as many of the value-creation cycles as possible, with monitored indicators for each.

- They are likely to generate stories. They are recognizable to members, that is, referring to effects in ways that resonate with their experience and aspirations.

- They amplify stories that refer to them. They reach beyond members’ perception, with enough aggregation and scale to transcend individual claims.

In other words, the quality of effect data is summarized by the question: what is the likelihood that a story will cross this data point and be amplified by it?

Well-formed contribution data. Good contribution data consist of a rich set of valuecreation stories that provide tight accounts of the flow of value across cycles. Characteristics of a well-formed value-creation story include:

- A clear protagonist: telling the story in the first person supports identification with the story teller as legitimate carrier of value across the framework

- A specific case: it addresses specific events, contributions, and changes as inspectable data points rather than generalities

- Completeness: it traverses at least the first four cycles and thus avoids skipping steps in the explanation 
- Plausibility: it details the causal links between adjacent cycles so that the flow of value becomes visible

Collecting good stories. This is a key factor. It is rare to get a good story in the first instance. One often starts with story snippets, unfinished stories, or stories with gaps in the causal links between cycles. Most good stories emerge by guided story-telling and follow-on conversations to revisit the story, fill in the gaps, and find out the ending after time has passed. Imagine participants were introduced to the framework several times and guided into telling their story by an experienced interviewer. In other projects, we have also provided training for specific participants (such as local coordinators) to act as "value detectives" following up clues and leads from the data to find stories. These coordinators have worked together to comment on each other's stories in a process of refining and improving them. Their knowledge of the local context allows them to assess and hone the plausibility of stories. Active engagement in the critique and refinement of stories renders participants more astute in identifying potential stories and sharpening them.

Complementarity. The more a story refers to indicators that are being monitored in each cycle the better it affords integration. This provides a complementarity that weaves the story into a bigger picture while the story enriches the meaning of each indicator it refers to with a person's lived experience of it. Good effect data set the stage for participants to tell sharp stories about how value flows from the intervention. With this grammar each side can strive to produce data likely to contribute to an integration process that will produce a more robust picture of the intervention. The framework thus acts as a boundary object by providing a language and a syntax for producing well-formed mixed-method data ready to contribute to an integrated picture. 
Again considering Figures 3 and 4 together illustrates how well-formed effect and contribution data enhance each other. In Figure 3, the survey that is mentioned under transformative value (top-right) sets the stage for the story in Figure 4 by providing quantitative data about changes in understanding of resilience. The first-person story of Figure 3 then enriches the survey by describing the experience of one case of transformation. By following a specific insight through the successive cycles into the narrator's life, the story explains how participation in the program contributed to the transformation. And the survey suggests that this story is far from being an isolated case.

\section{Initial Research Questions}

Research objectives are especially important in mixed methods as they provide a platform on which qualitative and quantitative questions are synthesized into integrated themes (Teddlie and Tashakkori, 2009:110). Rather than having separate QUAN and QUAL research questions, the framework follows the second strategy proposed by Plano Clark \& Ivankova (2016:43) where there is a single overarching research question with sub-questions for QUAN and QUAL.

In its original formulation, the framework was intended to frame a retrospective assessment of the value created by the learning of a community of practice. Since then, we have found that groups use the framework prospectively to create a vision and plan their activities. The graphic in Figure 5 includes the elements of the discipline that the framework brings to this prospective application:

- Within each value cycle a community can set specific aspirations. ${ }^{3}$ For each aspiration it is a good planning discipline to consider conditions to make aspirations realistic. 
- It is often useful to also think of risks and mitigation strategies to consider at each cycle.

Note that condition and mitigation strategies enrich the evaluation by providing additional parameters for explaining successes or failures in an intervention.

Once participants and stakeholders have negotiated their aspirations and considered conditions, risks, and mitigations for each value cycle, the evaluation needs to develop a set of indicators for which effect data can be collected. This is not a causal hypothesis but a frame for articulating contribution claims.

In some cases, we have asked community members and stakeholders to imagine aspirational value-creation stories about how the intervention can generate desired outcomes. Thus the evaluation starts with some initial aspirational stories that give a baseline for contribution data. These stories are best when they traverse projected indicators so the initial evaluation questions for effect and contribution can be integrated from the start. 


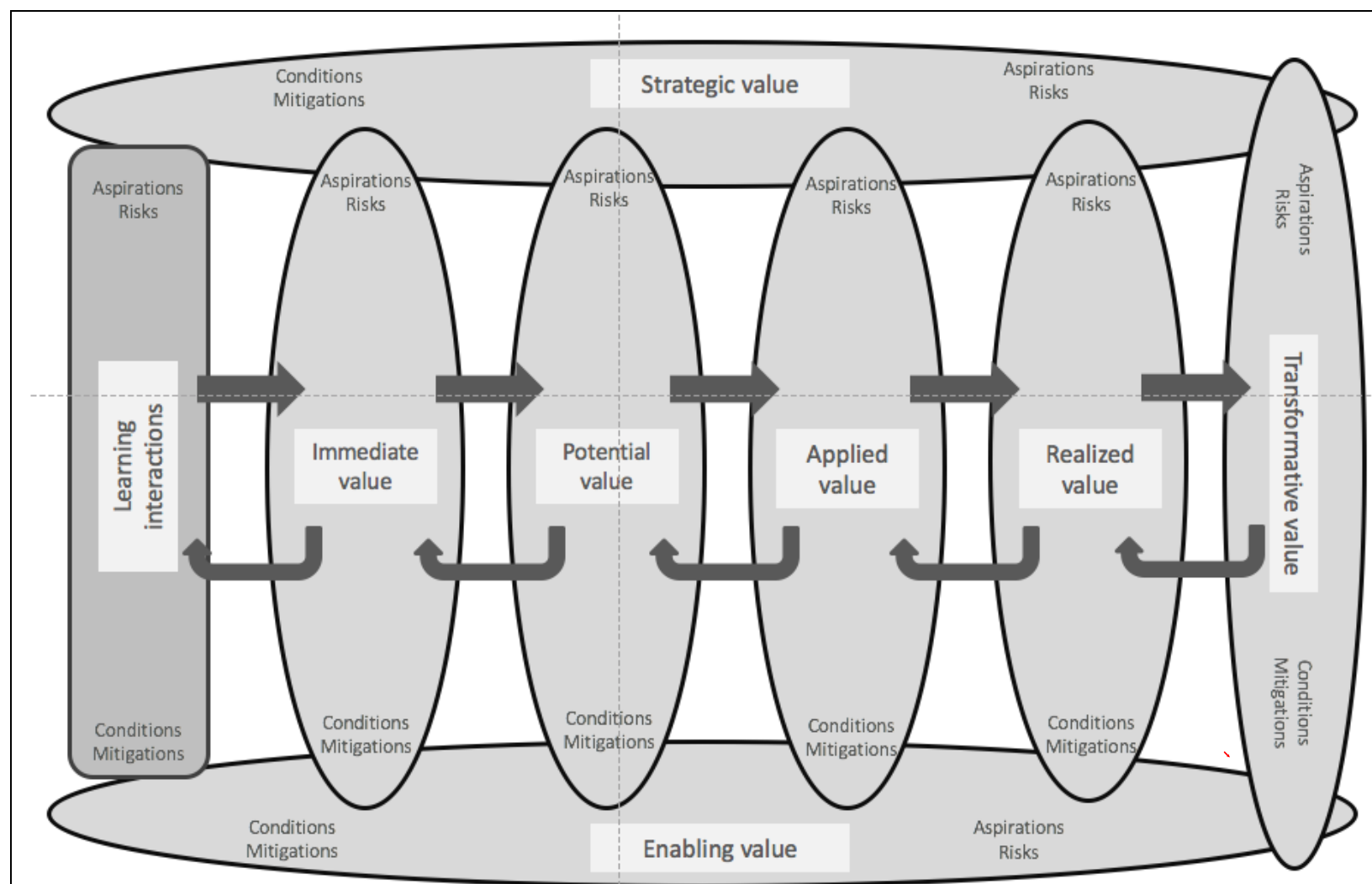

Figure 5. Aspirations/conditions and risks/mitigation at each value-creation cycle

\section{Dynamic and Integrated Research Design}

In a fully integrated mixed methods study we would hope to see integration happening at all stages of an evaluation in a dynamic and integrated process (Teddlie \& Tashakkori, 2006:23). If the framework is used in a purely top-down fashion, the initial set of aspirations is what the evaluation assesses. In social interventions, however, the full set of relevant indicators and stories is rarely known in advance. Aspirations and risks can change with new circumstances, achievements, and failures. Some may turn out to be unrealistic or irrelevant; new ones may emerge. 
The monitoring of indicators and the collection of value-creation stories can run in parallel: one does not have to wait for the other. In particular, one can start collecting valuecreation stories at any opportune moment in a project, even before the monitoring of indicators has yielded significant results. Value-creation stories are generated from two sources: from participants who have an experience of value-creation and from salient indicators that need to be contextualized in relation to the intervention. Note that these stories can be initiated at any cycle. In other words, they can run forward from an important activity; they can run backward, initiated by an effect in realized value; or they can go middle-out, triggered by an effect in the intervening cycles.

Indicators and stories point to each other iteratively throughout the evaluation process:

- Indicators to stories. As an indicator becomes salient (strong or weak) it suggests the need to collect some stories that refer to that indicator.

- Stories to indicators. Conversely a good story referring to some interesting effect suggests that there may well be an indicator worth monitoring more systematically.

The ongoing interaction and mutual references between the two kinds of data make for a dynamic and integrated research design. Questions about what effect data are meaningful to participants and what contribution stories can be amplified by effect data run iteratively throughout the research process. Quantitative and qualitative sampling are mutually defined and complementary. This dynamic strategy makes for an iterative version of what Teddlie and Yu refer to as sequential mixed methods sampling in their taxonomy of sampling strategies (2007:28). 


\section{Dynamic and Integrated Analysis, Interpretation, and Reporting}

Because of the iterative integration of sampling strategies, quantitative and qualitative analyses must happen in the same time frame. This is because the core of the analysis lies in integration, which is itself a form of analysis and interpretation. Integration creates a two-way reinforcement, which strengthens each data stream. On the one hand, the relevance and significance of indicators is increased by stories that anchor them in the experience of participants: stories help explain effect data in terms of the story-teller's participation in the intervention. On the other hand, the plausibility of a story is increased by reference to indicators that corroborate its statements; and the story’s relevance is amplified by indicators that show how representative it is likely to be. Indicators become meaningful through stories; stories become representative by referencing indicators. The quality of the analysis depends on the degree of integration between effects and contribution.

As suggested by the arrows of Figure 2, the framework lends itself to the construction of a matrix: the columns represent effect indicators at each value-creation cycle (as in figure 3) and the rows represent stories that traverse them (as in figure 4). Integrated analysis results in a tight matrix of indicators and stories referencing them. ${ }^{4}$ Hence the quality of the analysis reflects questions such as:

- How many stories traverse an indicator? Is that enough to provide plausible contribution of the intervention to the indicator?

- How many monitored data points does a story cross?

- Do empty cells in the matrix reveal missing links in a story?

This progressive integration calls for an evolving interpretation in which the narrative builds as the data come in. Over time the matrix fills out, tightens, and expands. As effect and 
contribution data reference and complement each other iteratively, the picture of the intervention's impact emerges and becomes sharper. The matrix is a kind of meta-inference. The use of a matrix is proposed as a mixed-method reporting device by Fetters et al (2013:2143) and by Miles and Huberman who argue for the use of matrices for analyzing qualitative data (1994). As a matrix, the framework is a joint-display tool for making meaning across different quantitative and qualitative data streams and communicating about results.

\section{Bridging Perspectives of Various Paradigms}

“I call for a paradigm dialog” Norman Denzin (2009:307)

A second area where boundaries are of concern to the mixed methods community is between the various ontological and epistemological paradigms that are relevant to its research methods (Creswell \& Plano Clerk, 2007; Shannon-Baker, 2015; Tashakkori \& Teddlie, 2003,). The composition of mixed methods research teams often involves more than one paradigm and we have seen the framework act as a boundary object between paradigms. Our collaboration with the Imagine Program is a good case in point.

Social learning theory does not fit cleanly within a single paradigm; but as the developers of the framework, if we had to locate ourselves in the paradigms familiar to the mixed methods community, we would choose a hybrid of pragmatism and contemporary constructivism. The rest of the team includes two critical realists and one post-positivist. In other words, a variety of perspectives $^{5}$. Let us briefly explore how each group recognizes its own perspective when engaging with the framework, starting with our own:

"We see the framework from a pragmatist perspective because its claims to knowledge are a result of engaging with the world. What works (or not) in practice is tested by running through value-creation cycles. Value-creation stories provide a disciplined 
way of collecting data about outcomes from actions. Re-integrating these valuecreation stories as learning loops into the intervention enables an ongoing reflection on practice as the basis for a collective inquiry toward what Dewey calls a more intelligent and better informed practice (see for example: Dewey, 1941/2008). The framework also reflects a central moral value of pragmatism, freedom of inquiry: individuals and communities are able to define the issues that matter to them and pursue those issues in the ways they find most meaningful (1925b/2008). As pragmatist constructivists we focus on the experience of value creation, holding that what counts as value is often different for different participants and stakeholders. The definitions of value at the different cycles are multiple and call for credible evidence from multiple perspectives. The setting of aspirations and indicators is open to contestation and negotiation. Claims about what matters and "what works" both reflect and act on relationships of power. Through the setting of aspirations by members and stakeholders, and through the use of their stories, the framework takes participant perspectives as essential pieces of data. It gives a discipline to the collection of stories by pushing the tellers to articulate relevant details about their experience of value creation. It scaffolds the building of a collective narrative about the value of the intervention. The resulting picture of the intervention is relevant because it embraces and brings into dialog the diverse voices of constituents and stakeholders.”

Two other members of the Imagine team are critical realists. They see value-creation cycles and stories as disciplined ways to talk about outcomes and mechanisms:

“The framework reflects the critical realist view that reality is more than just observable events. These events form key pieces of data but to explain processes and 
circumstances that produce those events/outcomes we need to understand the mechanisms and structures that have the potential to produce those events. The framework supports this explanatory endeavour with its emphasis on seeking to explain events with value-creation stories relating to causal attribution. In particular this supports the critical realist analytic method of "retroduction” (Danermark et al., 2002), which asks the question: what must the world be like for it to produce the outcomes we observe? The framework is also very compatible with the critical realist view that the social world forms part of reality: people’s variable beliefs and attitudes are part of that reality, which interventions may aim to influence. So the framework can be used to identify real world events produced by the attitudes or beliefs of people. The framework is compatible with the critical realist view that there is a shared reality albeit one that individuals may experience differently due to diversity in culture, power, gender, identity, etc. It is flexible enough to analyse context, mechanisms, and outcomes at the group level or be applied to subgroups or even individuals. So using the framework works well for a critical realist but I can see that it may be more difficult for people from phenomenological or post-modernist perspectives who are more interested in descriptions than explanations.”

One member of the Imagine team comes from a post-positivist perspective, and she does not hide her initial discomfort with the methodology:

"For me I see value as change, which is what I am used to measuring. When I heard that there would be no control group in Imagine, I was skeptical. Plus, we had to evaluate a multiplicity of outcomes, some of which were emergent rather than posed as hypotheses upfront. And we were thinking of sharing data to influence the intervention 
we were evaluating. I thought all that would really compromise the rigor of my methods. I should say that the framework to some extent compensated for the absence of control group for me. It is not a substitute, but it gives me more confidence that my conclusions are plausible, even in the absence of control groups, because it provides information on process as well as outcomes. Another thing is that when I proposed quantitative pre- and post-tests of resilience measures, the team was skeptical at first. But when I was able to show them that this would provide a baseline and a useful measure of realized value, they could see the point. Same thing with feedback forms, which supplied information on immediate value. So the framework allowed me to locate the contributions of my methods to the overall construction of a robust picture of the project."

The framework as a boundary object has allowed the team to work together and appreciate the contributions of other paradigms via their ability to strengthen the picture of the intervention. We consider these three paradigms because they were the ones we experienced in the project, but we believe the framework could also be used to bridge across other paradigms; it is a model that is close enough to the phenomenon to lend itself to multiple interpretations that can be integrated into a shared story.

In the case of multiple paradigms each data set and perspective can be kept separate but complementary (see Morse, 2003); or they can be in dialectical tension to negotiate the "set of assumptions, understandings, predispositions, and values and beliefs...” (Greene, 2007:12). Dialectical pluralism (Greene \& Hall, 2010; Johnson \& Gray, 2010, Johnson, 2015) “actively welcomes more than one paradigmatic tradition and mental model, along with more than one methodology and type of method, into the same inquiry space and engages them in respectful 
dialogue one with the other throughout the inquiry.” (Greene and Hall, 2010:124) We think that the framework as a boundary object offers another option: a mediated form of dialectical pluralism, in which the dialogical respect is mediated by a model of how social interventions create value. Perspectives can maintain their coherence at the same time as being interdependent. The different assumptions underlying each paradigm can interact, via the framework, by enriching the overall picture of the intervention in ways that reveal the value of their rigor and the partiality of their account.

\section{Axiological Commitments}

“Difference matters” - Sharlene Hesse-Bieber, (2015:xliii)

Up until now we have talked about the framework as a boundary object that bridges different approaches in the mixed methods community. In this section we consider how it can act as a boundary object in three axiological commitments typical of mixed methods research: between different constituents in participatory research; between research and practice in action research; and along relationships of power in an emancipatory approach to research. We view these axiological commitments as ethical stances rather than paradigms because they represent a different dimension and can be adopted in conjunction with various paradigms typical of mixed methods.

\section{Participatory Stance - an Intuitive, Recognizable Model}

Our initial goal in developing the framework was to enable members of communities of practice to monitor the value of their learning - without the need for a professional evaluator. Indicators and claims of plausible contribution had to make sense to participants as well as relevant stakeholders. To that end, the value-creation cycles are intuitive enough that participants can use them to articulate their aspirations, as well as the conditions required and the 
risks involved. The narrative genre of value-creation stories is intuitive enough that participants can learn it; with enough training, we find that they can spontaneously come forth with relevant value-creation stories in a form that contributes useful data.

The Imagine Program takes a radically participatory stance aimed at the co-production of the whole research process including outputs. Having a language that reflects at the same time the rigor of research and the intuition of participants is key to involving participants as coresearchers and co-producers of the output of the research. Indeed, the framework provides a shared language among diverse Imagine participants. The value-creation story in Figure 6 illustrates the function of the value-creation framework as a boundary object for non-academic participants. The annual research retreats mentioned in the story included academics, service providers, families, and youths: facilitated as boundary-crossing events, retreats were a key mechanism by which the Imagine programme involved multiple constituents directly in all phases of the research. Imagine researchers have also found that the framework is useful for communicating results outside academia because it does not require much translation. 


\section{Strategic}

The story is told by a peer trainer in the same resilience peer-training project as Figure 4.

\begin{tabular}{|c|c|c|c|c|}
\hline Immediate & Potential & Applied & Realized & Transformative \\
\hline $\begin{array}{l}\text { Whilst I have received } \\
\text { some formal training to } \\
\text { act as a peer trainer } \\
\text { drawing on my own } \\
\text { personal lived experience } \\
\text { of mental health } \\
\text { problems, I had never } \\
\text { been to a research event } \\
\text { of any kind before my } \\
\text { involvement with the } \\
\text { Imagine program. I was } \\
\text { surprised that I enjoyed } \\
\text { our first cross project } \\
\text { research meeting and felt } \\
\text { able to contribute to } \\
\text { discussions }\end{array}$ & $\begin{array}{l}\text { At this event I was } \\
\text { introduced to the } \\
\text { Value Creation } \\
\text { Framework which I } \\
\text { found very } \\
\text { understandable and } \\
\text { I agreed to learn } \\
\text { more about it and } \\
\text { co-present it to } \\
\text { other participants } \\
\text { attending the annual } \\
\text { Imagine Research } \\
\text { programme meeting }\end{array}$ & $\begin{array}{l}\text { Our presentation } \\
\text { helped other } \\
\text { Imagine } \\
\text { collaborators to } \\
\text { develop their } \\
\text { research and } \\
\text { evaluation plans. } \\
\text { Records from our } \\
\text { Imagine meetings } \\
\text { suggests that this } \\
\text { presentation has } \\
\text { resulted in more } \\
\text { systematic use of } \\
\text { the framework to } \\
\text { develop and } \\
\text { evaluate projects. }\end{array}$ & $\begin{array}{l}\text { At a personal level it } \\
\text { increased my } \\
\text { confidence in my ability } \\
\text { to grasp and } \\
\text { communicate concepts } \\
\text { to other people. It has } \\
\text { increased my } \\
\text { engagement in both } \\
\text { teaching and research } \\
\text { activities related to the } \\
\text { Imagine project and } \\
\text { beyond as a visiting } \\
\text { lecturer to students } \\
\text { studying to become } \\
\text { health and social care } \\
\text { professionals at the } \\
\text { University of Brighton. }\end{array}$ & $\begin{array}{l}\text { As a result of this } \\
\text { overall experience I } \\
\text { have decided that, } \\
\text { contrary to my past } \\
\text { educational } \\
\text { experiences, I do } \\
\text { have ability to } \\
\text { study in a more } \\
\text { formal academic } \\
\text { manner and have } \\
\text { started an Open } \\
\text { University } \\
\text { psychology course }\end{array}$ \\
\hline
\end{tabular}

\section{Enabling}

The story alludes to but does not explicitly describe all the enabling work done by the program organizers.

Figure 6. A personal story about the function of the value-creation framework as a boundary object for non-academic participants.

\section{Action-Research Stance - Changing the World Through Rapid Research Feedback}

The role of evaluation in the Imagine Program is formative as well as summative. All

Imagine projects develop resilience based interventions collaboratively and iteratively. They use

observed value indicators to learn what worked well about their interventions and what could be

improved.

This requires a dynamic research design with ongoing feedback loops. The framework depicts social learning in terms of loops across value-creation cycles. Indeed, we have seen many cases where feeding back value-creation stories into the learning of a community inspires others to adopt new approaches in their context, if the story is positive; or it warns them about 
what not to do, if the story is negative. In the project narrated in Figures 4 and 6, participants are encouraged to report back on how they have implemented their strategies and plans and what had happened as a result. These loops back from applied and realized value into the group’s activities generate new immediate value (the personal stories are interesting) and potential value (they suggest new ideas).

At the project level, effect data and value-creation stories provide material to be looped back into the intervention. In Imagine, for instance, the baseline surveys of measures of resilience in schools are used by staff to design their plans of action. Having indicators and stories that reflect the participants' experience contributes to the likelihood that feeding the research back into the intervention will have effects on practice. Feedback can be quite rapid: value-creation stories, or even partial value-creation stories, can be fed back as learning loops into the intervention as soon as they are collected.

\section{Emancipatory Stance - Redressing Power Imbalances}

The Imagine Program is explicitly committed to a social justice agenda. For instance, one goal is to help people get better at challenging sources of stigma and discrimination as a form of resilience. The program is intentionally structured to bring to the table the voice of youth with special needs and people with mental health challenges in order to advocate for changes in attitude and service delivery that reflect their own experience and their practice. The story of Figure 6 illustrates the transformative effects of using a boundary object to involve participants in a research program.

Dominant discourses in research, policy-making, and management have largely relegated the experience of practice to what Michel Foucault calls “subjugated knowledges” (1977). The experience of practice is often marginalized or assumed to be a receiver rather than a creator of 
knowledge. In our work on social learning the voice of practice is an essential component of social learning capability. The use of value-creation stories presupposes the legitimacy of the voice of practice as a source of evaluation data and learning loops. Involving participants in articulating their aspirations and risks at each value cycle is another area where the voice of practice is legitimized. By collecting these aspirations systematically, researchers can help participants articulate a change agenda to improve their lives.

The focus on value creation also surfaces issues of power: what works for whom and to what end? (Biddle \& Schafft, 2015) Setting aspirations usually involves multiple stakeholders with different views of what constitutes value or risk: Value for whom? Risk for whom? Who gets to decide what counts as value or risk, and what are realistic conditions or mitigation strategies? When used with multiple stakeholders, the framework systematizes an explicit focus on relations of power by surfacing the interests of different stakeholders at each cycle. This is especially true if aspirations for transformative value that include the voice of practice shape an action agenda for reform with a focus on increased social justice. Surfacing different interests in each value cycle provides a basis for developing strategies to negotiate, resist, challenge, or subvert differences in power.

\section{Conclusion}

While there is a trend toward integration, dialectic pluralism, and multi-paradigms, in practice it is not always easy for researchers from different approaches to talk to each other and to take full advantage of their differences. Boundary objects, especially of the structured kind, can mediate negotiations across boundaries. We have described our value-creation framework as an example of such a boundary object. It is not an attempt at reconciliation or removal of boundaries. It does not require a consensus beyond a commitment to its role as a boundary 
object in the service of evaluating, researching, and improving the same intervention. We have attempted to show how it has provided the Imagine Program with a shared language, which can be interpreted and acted on across various types of boundaries.

At the same time the use of the value-creation framework as a boundary object raises some questions, which we see as falling into five categories:

Quality of analysis. Does integration through a boundary object change the nature of collection and analysis of each data type? In large-scale projects what are sampling strategies for collecting representative value-creation stories? We need more systematic guidance about whom to select and how many stories are enough to yield plausible claims of contribution for large quantitative indicators.

Conditions, risks, and mitigation as data. The inclusion of conditions, risks, and mitigation is a fairly recent development in the framework. We need to understand better how these can be used as data to provide additional explanatory avenues for evaluation.

Presentation of results. While Imagine researchers have found the framework useful for communicating to different audiences, some questions remain. Once you have a matrix that is filled with robust data consisting of perhaps hundreds of stories, how do you present the results in a way that does justice to the complexity while also giving audiences a digestible synopsis? How do you extract from the matrix different views of the results for different types of stakeholders? We have not yet seen a comprehensive evaluation report that achieves this balance for large-scale interventions.

Quality of boundary engagement. To what extent does the use of a boundary object support deep dialogue across perspectives or, on the contrary, obviate such dialogue by 
facilitating collaboration without the need to fully understand other perspectives? In which cases is one or the other option better? Can a boundary object do both at once?

Using the framework for research. We have only seen the framework used for evaluation, but it would be interesting to know how it can be used as a tool for mixed methods research more generally.

These questions are urgent for making our framework useful for large-scale evaluation of social interventions. They also make us curious about the broader use of boundary objects for mixed methods research, the forms they take and the role they play. We believe these are fruitful areas for further inquiry. 


\section{References}

Biddle, C. \& Schafft, K.A. (2015). Axiology and anomaly in the practice of mixed methods work: Pragmatism, valuation, and the transformative paradigm. Journal of Mixed Methods Research, 9(4), 320-334.

Bryman, A. (2007). Barriers to integrating quantitative and qualitative research. Journal of Mixed Methods Research, 1(1), 8-22.

Creswell, J. W., \& Plano Clark, V. L, (2007) Designing and conducting mixed methods research. Thousand Oaks, CA: Sage.

Danermark, B., Ekstrom M., Jakobsen, L., and Karlsson, J.C. (2002) Explaining society: Critical realism in the social sciences. London, England: Routledge.

Denzin, N.K. (2009). Qualitative inquiry under fire: Toward a new paradigm dialogue. Walnut Creek, CA: Left Coast Press.

Dewey, J. (2008). Propositions, warranted assertibility and truth. In J. Boydston (Ed.), The later works of John Dewey, 1925 - 1953 (Vol. 14, pp. 168-188). Carbondale: Southern Illinois University Press. (Original work published 1941).

Dewey, J. (2008). The public and its problems. In J. Boydston \& J. Gouinlock (Eds.), The later works of John Dewey, 1925-1953 (Vol2, pp.235-372). Carbondale: Southern Illinois University Press. (Original work published 1925b)

Eser, U. (2002). Der Wert der Vielfalt: “Biodiversität” zwischen Wissenschaft, Politik und Ethik. In M. Bobbert, M. Düwel and K. Jax, editors. Umwelt -Ethik-Recht. Francke Verlag, Tübingen, Germany.

Fetters, M.D., Curry, L.A. \& Creswell, J. (2013). Achieving integration in mixed methods designs - principles and practices. In Health Services Research 48(6 Pt 2): 2134-2156. 
Flick, U. (2007). Designing qualitative research. London, England: SAGE.

Foucault, M. (1977) Power/knowledge: Selected interviews and other writings 1972-1977. New York, NY: Pantheon Books.

Greene, J. C. (2007). Mixed methods in social inquiry. San Francisco, CA: Jossey-Bass.

Greene, J. C. (2008). Is mixed methods social inquiry a distinctive methodology? Journal of Mixed Methods Research, 2(1), 7-22.

Greene, J., \& Hall, J. (2010). Dialectics and pragmatism: Being of consequence. In A. Tashakkori, \& C. Teddlie (Eds.), SAGE handbook of mixed methods in social \& behavioral research (pp. 119-144). Thousand Oaks, CA: Sage.

Hesse-Biber, S.N. (2015) Introduction: Navigating a turbulent research landscape: working the boundaries, tensions, diversity, and contradictions of multimethod and mixed methods inquiry. In S. Hesse-Biber \& R.B. Johnson (Eds.), The Oxford handbook of multimethod and missed methods research inquiry (pp. xxxiii-liii). Oxford, England: Oxford University Press.

Miles, M. N., \& Huberman, A. M. (1994) Qualitative Data Analysis: an expanded sourcebook. Thousand Oaks, CA: Sage

Johnson, R. B. (2015) Dialectical pluralism: A metaparadigm whose time has come. Journal of Mixed Methods Research. Advance online publication. doi:10.1177/ 1558689815607692 
Johnson, B. \& Gray, R. (2010). A history of philosophical and theoretical issues for mixed methods research. In A. Tashakkori \& C. Teddlie (Eds.), SAGE handbook of mixed methods in social \& behavioral research (pp. 69-94). Thousand Oaks, CA: Sage.

Leeuw, F. (2016) Understanding what is being evaluated: Theory-based evaluation. In M. Bamberger, J. Vaessen, and E. Raimondo, Dealing with complexity in development evaluation: A practical approach (pp. 88-108). Thousand Oaks, CA: Sage.

Mayne, J. (2012). Contribution analysis: Coming of age? Evaluation, 18(3), 270-280.

MMIRA Task Force (2016). The future of mixed methods: A five-year projection to 2020. Mixed Methods International Research Association. Retrieved from https://mmira.wildapricot.org/resources/Documents/MMIRA\%20task\%20force\%20re port\%20Jan2016\%20final.pdf

Morse, J. M. (2003). Principles of mixed methods and multimethod research design. In A. Tashakkori \& C. Teddlie (Eds.), Handbook of mixed methods in social and behavioral research (pp. 189-208). Thousand Oaks, CA: Sage.

Plano Clark, V. L. \& Ivankova, N. V. (2016). Mixed methods research: A guide to the field. Thousand Oaks, CA: Sage.

Shannon-Baker, P. (2015). Making paradigms meaningful in mixed methods research. Journal of Mixed Methods Research 10(4), 319-334.

Star, S.L. \& Griesemer, J. R. (1989) Institutional Ecology, ‘Translations’ and boundary objects: Amateurs and professionals in Berkeley’s museum of vertebrate zoology, 1907-39. Social Studies of Science, 19(3) 387-420.

Tashakkori, A., \& Teddlie, C. (Eds.). (2003). Handbook of mixed methods in social and behavioral research (1st ed.). Thousand Oaks, CA: Sage. 
Teddlie, C., \& Tashakkori, A. (2006). A general typology of research designs featuring mixed methods. Research in the Schools, 13(1), 12-28.

Teddlie, C., \& Tashakkori, A. (2009). Foundations of mixed methods research: Integrating quantitative and qualitative approaches in the social and behavioral sciences. Thousand Oaks, CA: Sage.

Teddlie, C., \& Yu, F. (2007). Mixed methods sampling: a typology with examples. Journal of Mixed Methods Research, 1(1) 77-100, Sage.

Wenger, E. (1998) Communities of practice: Learning, meaning, and identity. New York, NY: Cambridge University Press.

Wenger, E., Trayner, B, \& deLaat, M. (2011). Planning and assessing value creation in communities and networks. Rapport 18. Heerlen: Open University of the Netherlands, Ruud de Moor Centrum.

Wenger-Trayner, E. \& Wenger-Trayner, B. (2014) Learning in a landscape of practice: A framework. In E. Wenger-Trayner, M. Fenton-O’Creevy, S. Hutchinson, C. Kubiak, \& B. Wenger-Trayner (Eds.), Learning in landscapes of practice: Boundaries, identity, and knowledgeability in practice-based learning (pp.13-29). London, England: Routledge.

Wenger-Trayner, E. \& Wenger-Trayner, B. (2017) Learning to make a difference: Value creation in social learning spaces. Manuscript in preparation. 
Initially we designed the framework to help members of communities monitor the value of what they were doing and how they were making a difference (or not). Since an earlier version was published (Wenger, Trayner, and deLaat, 2011) we have seen the framework used in ways that we did not initially envisage, including social interventions, such as the Imagine Program, trainings, and events. This brief overview we provide here will be sufficient for the argument of this paper. A full treatment of the framework is available in book form (Wenger-Trayner, 2017).

2 We distinguish between, on the one hand, paradigms, which we take to refer to ontological and epistemological commitments; and on the other hand, ethical stances, which we take to refer to axiological commitments.

3 We call these aspirations rather than objectives as they are more open-ended than goals. This is especially true when the idea is applied to communities of practice, which would resist being managed by objectives, but it is also a better term for social interventions.

$4 \quad$ For instance, we have used large Excel sheets to capture and integrate data in this way.

5 These quotes come from a discussion we had about our respective paradigms. The discussion was transcribed and edited by the authors. 